\title{
REVIEW OF HOSPITAL MANAGER'S COMPETENCIES IN ASTANA
}

\author{
Ayagyoz Umbetzhanova ${ }^{1}$, Gulmira Derbissalina ${ }^{2}$, Vitaliy Koikov ${ }^{3}$, Lyazzat Karsakbayeva ${ }^{4}$, \\ Nasikhat Nurgaliyeva $^{5}$, Dina Akhmetova ${ }^{6}$, Bibinur Ibraimova ${ }^{7}$, Zhanagul Bekbergenova ${ }^{8}$, \\ Dameli Kassimova $^{9}$
}

\begin{abstract}
Currently, in the Republic of Kazakhstan, the institution of professional managers and transparent forms of health organizations management, including modern management technologies, are being implemented. Thus, sufficient professional competency of managerial decision-makers should be one of the most important factors in ensuring the development of a national health system and implementation of all current reforms in the industry. This article aims to investigate the high relevance of the evaluation of health care manager's competencies and the development of measures to improve its level.

In this cross-sectional study, we have analyzed managerial competencies of different levels of healthcare managers using a special questionnaire, which was developed by EPOS health management group to assess their competencies. We interviewed 61 managers of different levels. On the basis of feedbacks, core competencies and their possession by hospital managers were identified.

At the first stage, respondents were asked to assess the importance of different competencies required for their work activity. All levels of management showed the high practical importance of assessed competencies. Results of the basic level demonstrated a practical importance of competencies ranging from $73 \%$ to $85 \%$, the middlelevel managers were from $83 \%$ to $93 \%$, and senior level results were $97 \%$ to $98 \%$. The next stage of the survey was an assessment of respondent's average level of self-esteem for the competencies they possessed. Mid- level managers showed a higher possession of competencies than other levels, from $56.8 \%$ to $70.2 \%$; the basic level was from $46.9 \%$ to $59.6 \%$; and senior level was from $41.6 \%$ to $54.7 \%$. The questionnaire was designed in a way to highlight the training gaps as the difference between the importance attributed to the command of a given piece of knowledge, competency or skills, and the level of proficiency the managers are demonstrating currently. Finally, the third stage assessed the training required, wherein each management level has their specific training requirements. As research shows, senior managers have the highest level of required training. For senior level, the greatest needs for training are "self-management” and "quality management." For basic level, trainings are in "HR management" and "quality management." For middle managers, their training needs are in all domains of management.
\end{abstract}

There is a discrepancy between the required and the actual competencies that different levels of health managers' have. The largest gap between mandatory and existing competences exists at the basic level, in "Personnel Management." A gap in the mid-level was in "Information and Financial Management”; and it was in "Quality Management” for the senior level. The proposed questionnaire could help to identify the most important training required to fill these gaps.

UDC Classification: 614.2-005.336.2, DOI: http://dx.doi.org/10.12955/cbup.v2.474

Keywords: competency, assessment, healthcare, managers, training

\section{Introduction}

Public health is the greatest asset of the state and a national security factor. In the age of globalization and high technologies, the competitiveness of the state depends on its healthcare policies. In turn, the effectiveness of healthcare depends on the quality of management decision-making executed at various levels of management. Increasing number of research on this topic in recent years has shown that the major role in the high achievement of the healthcare system belongs to managers of medical organizations. In this study we assess level of competencies of healthcare managers in Kazakhstan and

\footnotetext{
${ }^{1}$ Ayagyoz Umbetzhanova, Astana Medical University, Kazakhstan, ayatemir@gmail.com

${ }^{2}$ Gulmira Derbissalina, Astana Medical University, Kazakhstan, derbissalina@gmail.com

${ }^{3}$ Vitaliy Koikov, Republican Centre for Health Development, Kazakhstan, koykov@inbox.ru

${ }^{4}$ Lyazzat Karsakbayeva, Astana Medical University, Kazakhstan, lz.kars@gmail.com

${ }^{5}$ Nasikhat Nurgaliyeva, Astana Medical University, Kazakhstan, nnur-2007@mail.ru

${ }^{6}$ Dina Akhmetova, Astana Medical University, Kazakhstan, dina_ahmetova1809@mail.ru

${ }^{7}$ Bibinur Ibraimova, Astana Medical University, Kazakhstan, ibs_nuri_85@mail.ru

${ }^{8}$ Zhanagul Bekbergenova, Astana Medical University, Kazakhstan, zhanna_bekbergen@mail.ru

${ }^{9}$ Dameli Kassimova, Astana Medical University, Kazakhstan, delmi_87@mail.ru
} 
estimate their training needs. In fact, the scientific community has been actively investigating the issues of identifying required competences for managers in hospital management, such as the works of Kak \& Bart (2001), Lane (1998), Mohd-Shamsudin (2012), and Landry (2012). The literature review was conducted, to investigate the experience in this field, including Mansfield (1999), Fleishman (1969), Lockhart (2009), and Hudak (2000).

\section{Methodology}

The survey was performed among different levels of healthcare managers. The subjects of the study were managers at various levels; the criteria for inclusion in the study were written down in job descriptions of personnel management functions. Thus, it was identified that three levels of management were: basic (linear) level, mid-level, and senior level. The total number of respondents was 61: 5 senior managers, 45 mid-level managers, and 11 linear-level managers. The object of research was JSC Republican Diagnostic Center, located in Astana, Republic of Kazakhstan. The object was chosen because of its organizational structure, which contains the largest number of administrative and structural units.

In order to assess the current state of management competency of the managers in health organizations, we used the managers' competencies evaluation model, based on the questionnaire developed by EPOS experts (EPOS, 2010). The questionnaire consists of closed- and open-ended questions. Respondents were asked to assess, on a scale from 1 (“completely irrelevant”) to 7 ("extremely important"), the average level of practical importance of the knowledge, competencies and skills needed on average by the healthcare managers in Kazakhstan, and the average level of proficiency of such knowledge, competencies and skills thereof, using the same scale. Questions are related to the six areas of activity, which are: (1) self-management, (2) planning and assessment, (3) Human Resource Management, (4) information and financial management, (5) facilities and materials management, and (6) quality management, monitoring and evaluation. Each group (domain) includes four key competencies for more detailed description of the qualities those are required by a modern manager in healthcare.

The first domain includes such competencies as communication and presentation, time management, negotiation skills, and feedback (ability to give and receive feedback). The second domain includes: problem identification, planning, project management, and change management. The third domain includes supervision, performance management, management of labor relations, and team development. The fourth domain includes: information management, data collection and analysis, cost analysis, and budgeting. The fifth domain includes: technologies assessment, drugs management, equipment maintenance, and infrastructure and facility management competencies. The last domain includes: knowledge of basic quality principles, quality management, basic concepts of monitoring, and basic concepts of evaluation.

Formed database was statistically processed using the methods of quantitative analysis. For clarity and comparison charts and tables were constructed. For the analysis, we calculated the arithmetic mean (M) and the mean error value (m).

\section{Results and Discussion}

The assessment of competency was conducted for medical organization's managers of different levels (senior, middle, and linear), to identify the training needs. The survey consisted of several parts: assessment of the practical importance of the knowledge, competencies and skills needed on average by the healthcare managers. Then, self-assessment of an average level of proficiency of such knowledge, competencies and skills was conducted. Lastly, we assessed training needed. 
At the first stage, respondents were asked to rate the importance of each group of competencies for their activities. Figure 1 illustrates the results of the assessment of practical importance of the six domains of competencies for all three levels of management.

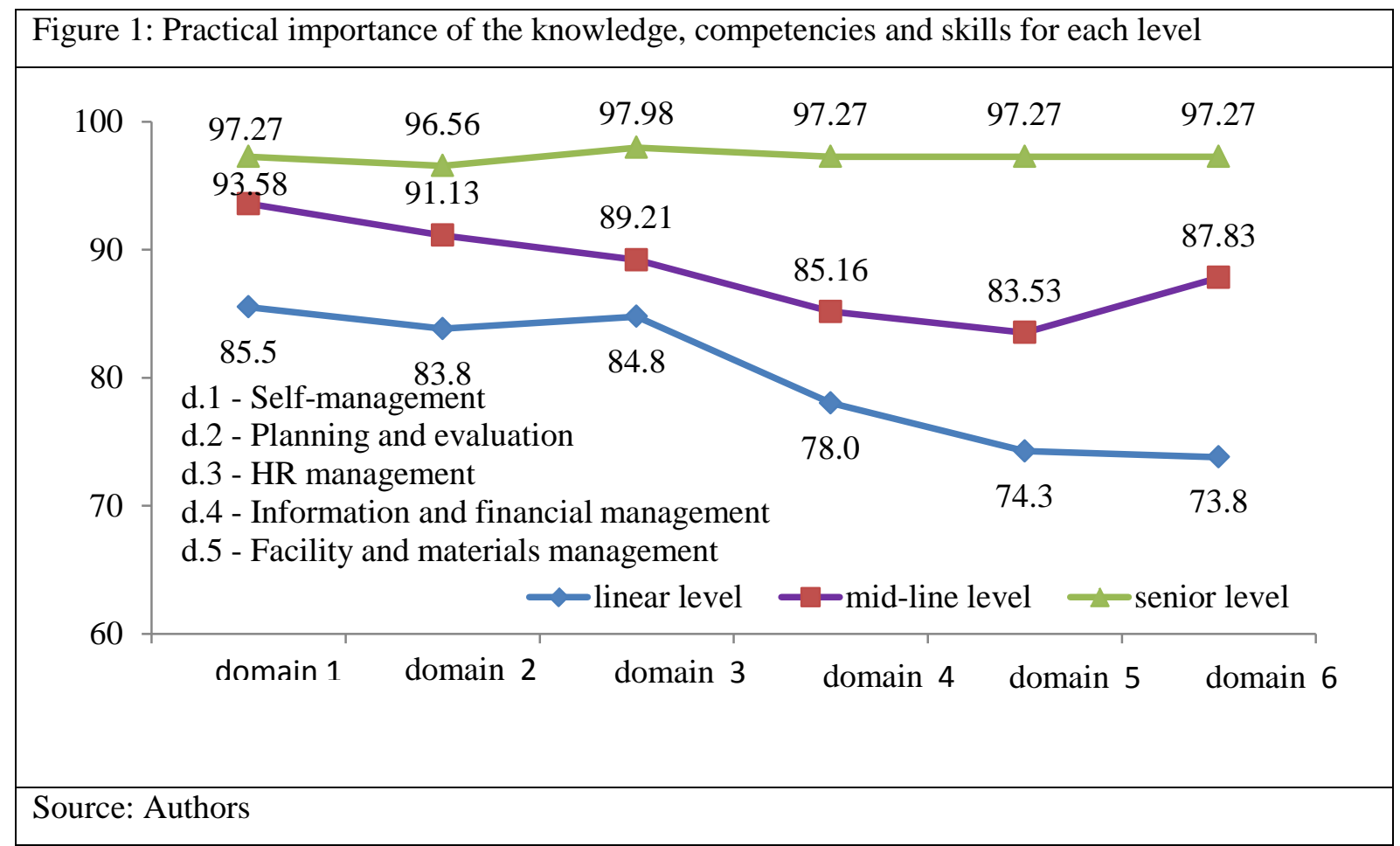

All levels of management noted a relatively high practical importance in the assessment of the domains of competencies for their activities. Most of the responses were at the top of the scale. However, the highest was assessed by senior managers. The results of the linear level were from $73 \%$ to $85 \%$; the middle managers level was from $83 \%$ to $93 \%$; and the senior level results were between $97 \%$ and $98 \%$.

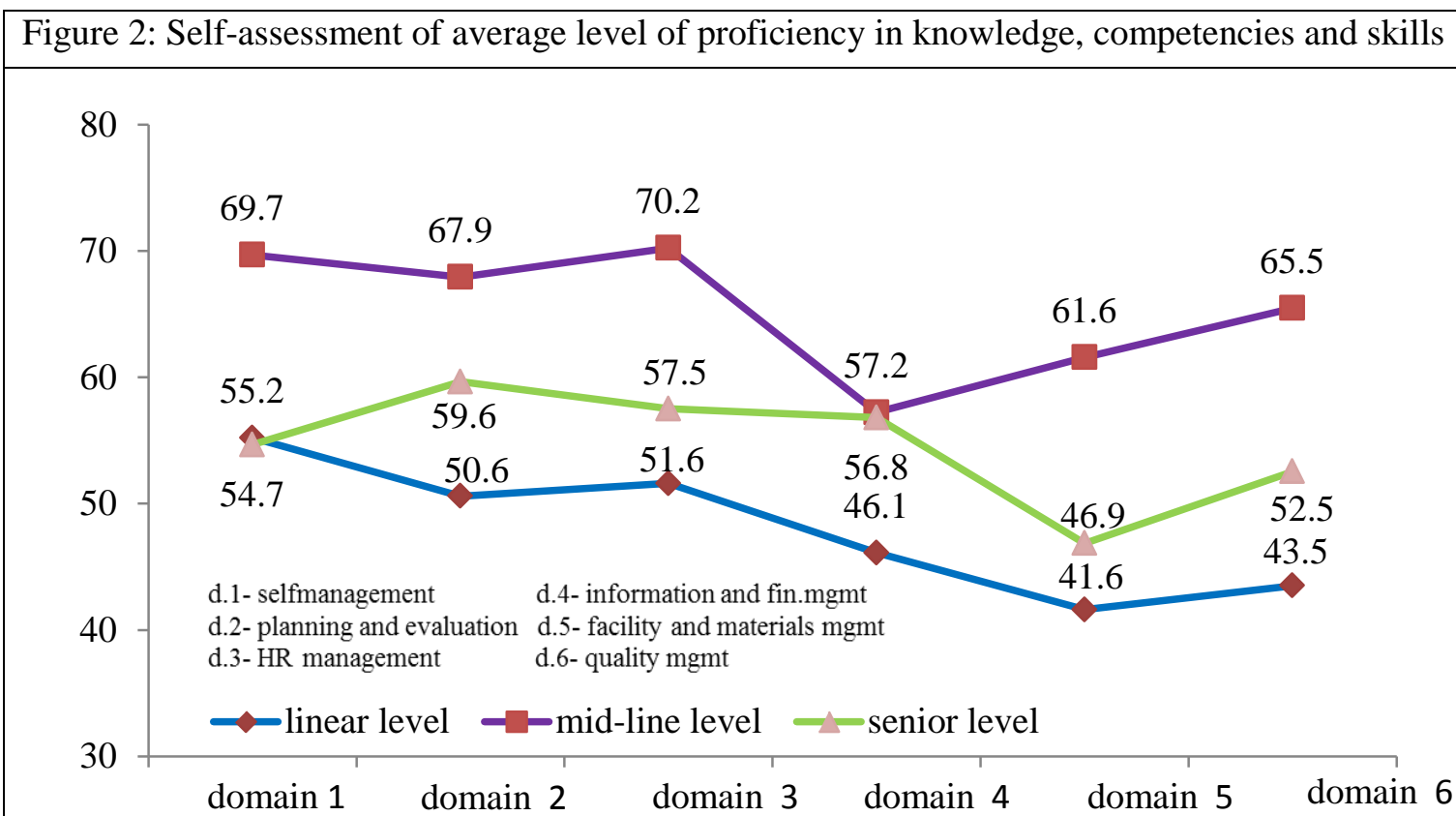

Source: Authors 
The next stage of the survey was an assessment of the respondent's self-esteem for the average level of competencies they possessed. The mid-level managers demonstrated the highest rate, which presupposed good potential in future. At the same time, a low self-esteem of senior managers can be attributed to the high level of expectation and requirement associated with higher positions, for more rigorous content and greater awareness of their activities. The results are shown in Figure 2.

The questionnaire was designed to highlight the training gaps as the difference between the importance allocated to the given knowledge, competency or skills and the level of proficiency the managers currently demonstrate. The practical importance and proficiency were assessed on a scale from 1 to 7. Table 1 summarizes the results of the training gap assessment in all domains of competencies for all levels of management. Each management level has its own training requirement. As the research shows, senior managers have the largest gap in training. For senior level, the greatest needs for training are "self-management" and "quality management." For basic level, trainings are in "HR management" and "quality management." For middle managers, their training needs are in all domains of management.

\begin{tabular}{|l|r|r|r|r|r|r|}
\hline \multicolumn{1}{|l|}{ Table 1: Evaluation of training needs } \\
\hline & $\begin{array}{c}\text { Domain 1 } \\
\mathbf{( \% )}\end{array}$ & $\begin{array}{c}\text { Domain 2 } \\
\mathbf{( \% )}\end{array}$ & $\begin{array}{c}\text { Domain 3 } \\
\mathbf{( \% )}\end{array}$ & $\begin{array}{c}\text { Domain 4 } \\
\mathbf{( \% )}\end{array}$ & $\begin{array}{c}\text { Domain 5 } \\
\mathbf{( \% )}\end{array}$ & $\begin{array}{c}\text { Domain 6 } \\
\mathbf{( \% )}\end{array}$ \\
\hline $\begin{array}{l}\text { Linear } \\
\text { level }\end{array}$ & 25.2 & 28.4 & 32.6 & 29.7 & 30.3 & 30.6 \\
\hline Mid-level & 24.4 & 23.6 & 20.5 & 28.4 & 22.9 & 23.1 \\
\hline $\begin{array}{l}\text { Senior } \\
\text { level }\end{array}$ & 39.8 & 36.9 & 34.8 & 32.7 & 37.6 & 41.9 \\
\hline Source: Authors & & & & & \\
\hline
\end{tabular}

\section{Hospital manager's competencies improvement}

To achieve the best performance in healthcare, special and high-level requirements must be imposed to the quality of educational programs, e.g. on-site training, retreats and cycles, master classes, etc. (Stefl, 2008). One of the requirements for educational programs should be their evaluation, in terms of both the listener and the user. In this case, there should be an evaluation of the patients and the supervisors. Routine assessment of manager's competencies, by self-assessment and "360 degrees" techniques are considered appropriate to assess the knowledge "output." Then, short-term and longterm monitoring should be done in the future to trace how the manager uses this knowledge in practice, distribute their experience and, most importantly, how it affects their performance.

Undoubtedly, the experience is an indispensable factor in the development of management competency; however, at the same time, one of the key elements is the continuous professional development. Results depend on the professional development based on well-thought-out planning and the goals of meeting the objectives. Due to rapid changes in the healthcare sector, as a result of reevaluation and changes in the roles and functions of professionals in healthcare, the ability to learn from experience and to plan for change is essential. The study of literature and conducted research in this area has led to the conclusion that the formation of a professional portfolio, or Personal Development Plan (IDP), will be a stimulus for the development and monitoring of learning outcomes (Liang, 2010). Individual Development Plan (IDP) or Personal Plan Development (PPD) is a tool that helps an employee, systematically and purposefully, develop his or her necessary skills and qualities. IDP is a document that describes the development and actions, which will help to achieve one's goals. 
Thus, we propose the following algorithm to improve the competence of hospital managers in medical institutions. Figure 3 illustrates a flow diagram of a competency improvement algorithm for hospital managers.

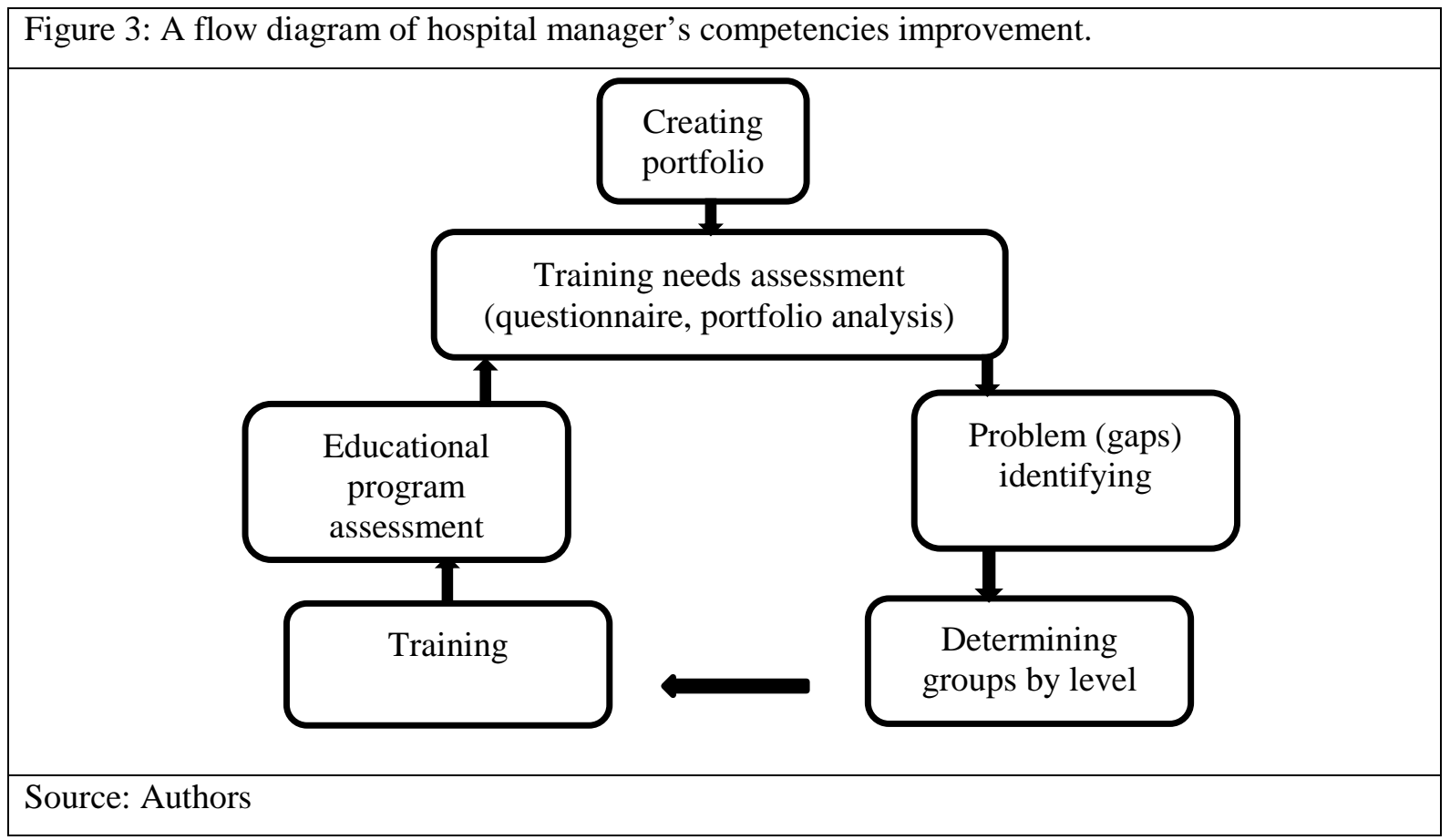

HR department forms manager's portfolio, which reflects previous learning cycles, seminars, workshops, participation in projects. Department of Education identifies training needs through questionnaires and portfolio analysis. After identifying the issues, we formed groups according to their training needs and the level of management-the next stage is training. An important point is the subsequent evaluation of the educational program effectiveness; it could be Kirkpatrick's model, a 360-degree assessment, or any other assessment tools. Specialist's professional development is a continuous cycle. Algorithm, designed for hospital manager's competencies improvement, could be used to enhance the process of continuous professional development. In doing so, we have developed the following recommendations:

1. Use competency model proposed in the paper as a standard tool for analyzing the competencies of healthcare managers.

2. Assess educational programs in the management of healthcare organizations in terms of both short- and long-term results, to monitor the implementation of new knowledge into the organization management.

3. Intensify the model of continuous professional development through the creation of individual development plans, which would take into account all previous training seminars, workshops, participation in projects, conferences, and publications (e.g. manager's portfolio), considering each manager's individual needs in training.

4. Use competency-based approach to assess potential candidates for the position during formation and certification process of healthcare managers.

\section{Conclusion}

All levels of management have insufficient competencies possession necessary for manager's routine activities in the medical organization. The basic-level manager's results were the lowest in "administrative management" domain of competences at 41.5\%, and showed high demands for training in "Personnel Management" at 32.6\%. Among mid-level managers, the lowest score was in 
the "information and financial management" domain at 57.2\%; the highest training needs in the same domain was at $28.4 \%$. Among senior level respondents, the lowest self-esteem was in "administrative management" domain at $46.9 \%$; the highest training required was in "Quality Management" competencies domain at $41.9 \%$.

There is a discrepancy between the required and the actual competencies that different levels of health managers' have. The largest gap between mandatory and existing competences exists at the basic level, in "Personnel Management." A gap in the mid-level was in "Information and Financial Management"; and, it was in "Quality Management" for the senior level. The proposed questionnaire could help to identify the most important training required to fill these gaps.

\section{References}

EPOS Health Management. (2010). Assessment of Current Needs in Health Management Training in the Republic of Kazakhstan.

Fleishman, E.A., \& Bartlett, C. (1969). Human Abilities. Annual Review of Psychology, 2(20), 349-380.

Hudak, R.P., \& Brooke, P. (2000). Identifying Management Competencies for Health Care Executives: Review of a Series of Delphi Studies. Retrieved from http://www.ncbi.nlm.nih.gov/pubmed/11183260

Kak, N., \& Bart, A. (2001). Measuring the Competenceof Health Care Providers. Operations Research Issue Paper, 2(1). Bethesda, Maryland: USAID.

Landry, A., \& Stowe, M. (2012, May). Competency Assessment and Development among Healthcare Leaders: Results of a Cross-Sectional Survey. Health Services Management Research, 25(2), 78-86.

Lane, D., \& Ross, V. (1998). Declining Competencies and Performance Indicators for Physician in Medical Management. American Journal for Preventive Medicine, 3(14).

Liang, Z., \& Howard, P. (2010). Competencies Required by Senior Health Executives in New South Wales in 1990-1999. Australian Health Review, 4(1), 52-58.

Lockhart, W., \& Backman, A. (2009). Health Care Management Competencies: Identifying the GAPs. Health Management Forum 22(2), pp. 30-37.

Mansfield, R. (1999). What Is “Competence” All About? Competency, 6(3), 24-28.

Mohd-Shamsudin, F., \& Chuttipatana, N. (2012). Determinants of Managerial Competencies for Primary Care Managers in Southern Thailand. Journal of Health Organization and Management, 26(2), 258-280.

Stefl, M. (2008). Common Competencies for All Healthcare Managers: The Healthcare Leadership. Journal of Healthcare Management, 53(6), 360-373. 